\title{
WestVirginiaUniversity。
}

Department of Economics

Working Paper Series

\section{Leadership and Motivation for \\ Public Goods Contributions}

Bryan McCannon

Working Paper No. 15-24

This paper can be found at the College of Business and Economics

Working Paper Series homepage: 


\title{
LEADERSHIP AND MOTIVATION FOR PUBLIC GOODS CONTRIBUTIONS
}

\author{
Bryan C. McCannon* \\ West Virginia University \\ \& Center for Free Enterprise
}

28 June 2015

\begin{abstract}
Results from a leader-follower public goods game are presented. An individual, when randomlyselected to make a contribution knowing that others will observe the selection, gives more than one does in the simultaneous-move public goods game. Followers adopt a quasi-matching strategy where they systematically donate less than the leader, but contribute more when the leader does and contribute less when the leader free rides. The net result is increased provision of a public good when contributions are sequential. The results highlight that psychological preferences, rather than solely social preferences, can explain behavior.
\end{abstract}

Keywords: experiment, leadership, psychological game theory, public goods, social preferences

\footnotetext{
* Department of Economics, 1601 University Avenue, Morgantown, WV 26506 USA, bryan.c.mccannon@gmail.com, (607) 857-7411

I would like to thank Claudio Detotto, Martin Dufwenberg, Joseph Guse, Todd Palmer, and Mark Wilson for helpful discussions and participants at the Business Research Consortium, Southern Economic Association, and BonaBusiness Research Seminar. I also appreciate the financial support from the Koch Foundation and the Clare College at Saint Bonaventure University, especially David DiMattio, for encouraging and financially supporting the research. I also thank Kim McCannon for being a lovely assistant during the experimental sessions.
} 


\section{INTRODUCTION}

A classic dilemma in public economics is how to discourage free riding and encourage contributions to public goods. A significant amount of experimental research has investigated this (Ledyard, 1995; Zellmer, 2003; Chaudhuri, 2010) dating back to the early studies of Marwell and Ames (1981) and Isaac, McCue, and Plott (1985). In the standard public goods game considered, individual contributions improve the outcome for others, but have a negative net effect on personal benefit i.e., the marginal return to the individual for each dollar contributed is less than one dollar.

To rationalize the contributions that are made, these works typically reference social preferences, or rather, "other-regarding" preferences (Fehr and Fischbacher, 2002). It is argued that there exists a component to each person's utility function that incorporates the well-being of the other players. Examples of social preferences are altruism, inequality aversion, egalitarianism, and fairness. This provides a tradeoff between personal gain and the benefit of others that can explain the lack of complete free riding.

An alternative argument promoted here is that psychological preferences are also important to explaining behavior. In psychological game theory, first introduced by Geanakoplos, Pearce, and Stacchetti (1989) and extended to extensive-form games by Battigali and Dufwenberg (2009), the preference ordering over the set of possible outcomes of a game can be made dependent on other players' beliefs regarding one's strategy selections, rather first-order beliefs, or a player's beliefs on other players' beliefs regarding one's strategy, second-order beliefs, or so on. An example of a psychological preference is guilt and guilt aversion. ${ }^{1}$ The important distinction between social preferences and psychological preferences is that in the former an individual cares about the outcome of the game, while in the latter a player is concerned with how others view the strategy taken.

In standard public goods games, one is, for the most part, unable to differentiate social and psychological preferences. This is due to the fact that choices are made not only

\footnotetext{
${ }^{1}$ Huang and $\mathrm{Wu}$ (1999) discuss how psychological game theory can act through social norms to reduce deviant, criminal behavior.
} 
anonymously, but also simultaneously. ${ }^{2}$ In practice, though, public goods contributions are frequently made sequentially. A fund-raising campaign, for example, may first rely on a large initial donor before marketing the project to other targeted donors. Sequential public goods contributions allow for leadership decisions to influence outcomes.

If psychological preferences are not important, then an individual will simply trade off personal gain and the outcome obtained by others. In fact, a theoretical model is presented where if only social preferences matter, the leader contributes less than the followers. Alternatively, if psychological preferences are important drivers, then being in a leadership position, where others will observe and respond to your giving, should encourage greater contributions.

To appreciate the role of leadership and psychological preferences on decisions, experiments of the Public Goods Game are contributed. In the design used, subjects are put into groups of four and are each endowed with five experimental dollars. One is selected at random to make his contribution first. The randomly-selected leader's contribution is made public to the other members of the group before they make their contributions. The total amount given is tripled and evenly shared. In a second treatment, the four in the group each make a contribution without knowing the offer of any other person.

Results show that leaders make larger contributions to the public good than in situations where there is no sequencing of decisions. Furthermore, followers adopt a quasi-matching strategy. When the leader makes a larger contribution, the followers do so as well, but when the leader free rides, so too do the followers. The net effect, though, is that sequential public goods contributions outpace simultaneous giving. The results, then, provide support for psychological preferences also being an important component of behavior.

Additionally, choices made if selected as the leader are collected along with contributions offered if a follower, knowing the leader's giving level. This allows for an investigation of switching behavior of an individual and how this responds to leadership. Not only do subjects pull back offers when not acting as the leader, but the magnitude of their retrenchment depends on the contribution of the leader. This is further strong evidence that psychological preferences are important drivers of outcomes.

\footnotetext{
${ }^{2}$ An important exception is the experimental design of Dufwenberg, Gächter, and Hennig-Schmidt (2011) were they use different framing techniques to explore psychological preferences. They do not, though, attempt to differentiate it from social preference setups.
} 
Sequential contributions to public goods were first investigated theoretically by Varian (1994). He illustrates that with diminishing returns and heterogeneous valuations, there exist environments where less is contributed than the simultaneous-move game. Sequential contributions, though, allow for emotions, based on beliefs about play of others, to be expressed. For example, Battigalli and Dufwenberg (2007) formulate guilt, by letting other players down and corresponding guilt aversion behavior, in psychological games. Dufwenberg, Gächter, and Hennig-Schmidt (2011) apply this theory to public goods contributions. They conduct experiments on the Public Goods Game investigating the accuracy of psychological game theory at explaining play. Their focus is on the framing of the game to the subjects and its effect on players' beliefs. Strong evidence is presented that changes in the presentation of the game adjust subjects' beliefs and, consequently, contributions.

This is not the first experimental investigation of sequential public goods contributions. Levati, Sutter, and van der Heijden (2007) consider sequential public goods experiments with one player selected at random to be the leader. The focus is on asymmetric endowments and incomplete information. The aggregate outcomes they find match those identified here in that leaders make larger contributions and followers' donations adhere to those of the leader. They do not investigate the determinants of individual-level behavior, as is done here. Güth, Levati, Sutter, and van der Heijden (2007) introduce the ability of a leader to exclude a player in the next round of a repeated game and show that this increases contributions further. Gächter, Nosenzo, Renner, and Sefton (2012) investigate how the attributes of the individual explain the heterogeneity of leader contributions in such environments. Andreoni, Brown, and Vesterlund (2002) consider a public goods situation where players have ideal aggregate contribution levels. Sequential contributions, then, predict free riding by the first mover. They show, indeed, contributions are less by the leader than the follower and total giving is below simultaneousmove contributions. Relatedly, Gächter, Nosenzo, Renner, and Sefton (2010) compare and contrast a similar two-player public good contribution, but focus on asymmetric returns to donations. They too find that aggregate contributions are lower in the sequential move treatment when the player who values the public good more moves first. Alternatively, Haigner and Wakolbinger (2010), Rivas and Sutter (2011), and Arbak and Villeval (2013) consider public goods contributions when subjects can choose to donate first before other members. Voluntary leadership leads to higher contributions than exogenously-selected leadership. This matches the 
findings of Potters, Sefton, and Vesterlund (2005). They consider two-player voluntary contribution games where only one player is informed of the value of the public good. Allowing a voting round to determine whether the informed must make her contribution first reveals that, frequently, the players unanimously agree to sequence the contributions. This leads to greater giving than treatments with exogenous timing. They do not allow for differing sizes of contributions. In a follow-up project, Potters, Sefton, and Vesterlund (2007) differentiate signaling by the informed leader from the possibility of social preferences. They fail to find any difference between giving in the sequential and simultaneous-move game without the asymmetric information.

The results presented here contribute to this literature by focusing on the individual-level decision making. This is possible due to the experimental design employed. By randomly selecting the leader after each subject has made his or her choice of contribution as a leader, the amount offered can be compared to what was actually given if, instead, chosen to be a follower. ${ }^{3}$ The two-step decision process allows for a study of both leadership choices, along with shirking and matching decisions as a follower. Hence, rather than focus on endogeneity of leadership, asymmetric information/endowments/returns, or exclusion, the work here is able to investigate, in depth, the utility function driving behavior.

The work also contributes to the growing literature on leadership in economics. Weber, Camerer, Rottenstreich, and Knez (2001) report on experiments where a randomly selected member of the group attempted to facilitate coordination. Komai, Grossman, and Deters (2011) present results from an experiment where the payoffs take the scenario of a public good nature or one of coordination. Treatments vary by whether all subjects or just a leader is informed of which scenario is active. They present results indicating that if the information is concentrated with the leader, so that followers only observe the leader's choice, public good contribution rates are higher. There was not an important difference between leader-follower and simultaneous investments in the coordination scenario. The work is extended to include the salience of gender

\footnotetext{
${ }^{3}$ Arbak and Villeval (2013) conduct a related analysis. In their design if two or more volunteer to lead, one is selected at random and the others become followers. They extend their analysis to study an ordered variable of revision up, down, or no-change. They show that revision is driven by gender and leader contribution, as is shown here, but their results suffer from endogeneity and don't consider nonlinear effects. Also, Gächter, Nosenzo, Renner, and Sefton (2012) employ a similar design. They classify individuals based on whether they provide high, low, or intermediate contributions when a follower. They show that leader contributions are correlated with follower type and conclude that driving leader contributions is social concerns. It does not, necessarily, study switching behaviors, but rather correlation between type of follower and leadership choices.
} 
in Grossman, Komai, and Jensen (2015). Similarly, Sahin, Eckel, and Komai (2015) also experimentally contrast behavior in public goods and coordination games. They differentiate leadership as "leading by example" from managerial cheap talk suggestions. They do not, though, find important differences in the types of leadership in the public goods treatments. Leadership is more effective for coordinating activities. Ertac and Gurdal (2012) investigate leadership in risk-taking decisions for a group. In a social psychology investigation of leadership in public goods, Van Vugt and De Cremer (1999) had participants play one round of a threshold public good game and then rate, on a one to seven scale, on their preference for having each of six "types" of leaders in such a setting. The subjects' most-preferred type of leader was "democratic" who collects desired contribution levels from all members of a group before making giving decisions.

These are just references to experimental work on leadership. For theoretical investigations to the study of the economics of leadership see Hermalin (1998) Komai, Stegeman, and Hermalin (2007), Komai and Stegeman (2010), and Lazear (2012).

Finally, the results suggest an alternate explanation for using sequential donations in fundraising campaigns. Vesterlund (2003) and Andreoni (2006) document and discuss the practice of fundraising announcing past contributions. The theoretical environment they explore is a signaling model, rather than the behavioral framework explored here. The announcement of a substantial donation before soliciting additional contributions, along with signaling the value of the project to the uninformed, may also tap into psychological features of one's preferences that elicit greater donations from both following and leading contributors. Relatedly, Andreoni and Petrie (2004) show that information and identification of donors can increase contributions.

Section II describes briefly the theoretical framework, while Section III describes the experimental design and procedures. Section IV presents the results. A concluding discussion occurs in Section V.

\section{THEORY}

The objective is to outline a straightforward theoretical framework of a public goods game that incorporates psychological preferences and differentiates predictions from outcomes 
with individuals who have selfish or social preferences. The model presented is an extension of the environment developed by Dufwenberg, Gächter, and Hennig-Schmidt (2011).

Consider a public goods game with four players labeled 1,2,3, and 4. Let $P=\{1,2,3,4\}$ be the set of players. Each player selects an action $a_{i} \in A_{i}=\{0,1,2,3,4,5\}$, which represents her contribution. Let $b_{i j}$ denote $i$ 's "first-order belief" about $j$ 's choice $(i \neq j ; i, j \in P)$, i.e., $b_{i j}$ is the mean of a probability measure $i$ has over the possible values over $A_{j}$. Let $c_{i j i}$ denote $i$ 's "second-order belief" about $b_{j i}$.

If individuals are standard wealth maximizers, then their payoff function is

$$
u_{i}{ }^{W}(a)=5-a_{i}+0.75\left(a_{1}+a_{2}+a_{3}+a_{4}\right)
$$

( $i \in P)$ where $a=\left(a_{1}, a_{2}, a_{3}, a_{4}\right)$ is the contributions of the four players. As a consequence, in the Nash equilibrium of the simultaneous-move game $a_{\mathrm{i}}{ }^{*}=0$ for all $i$, or rather, full free riding with no public good contributions arises.

Alternatively, suppose individuals have social preferences where they care about not only their own outcome, but the earnings of others. The payoff function can be expressed as

$$
u_{i}^{S}(a)=5-a_{i}+0.75\left(a_{1}+a_{2}+a_{3}+a_{4}\right)-\sigma_{i} S(x)
$$

$(i \in P)$ where $x$ is the difference between the average contribution of the other three players, $x=$ $\bar{a}_{l}-a_{i}=\left(a_{j}+a_{k}+a_{l}\right) / 3-a_{i}$ where $j, k, l \neq i$. The parameter $\sigma_{i}=0$, then represents selfish preferences, while $\sigma_{i}>0$ allows for social preferences to be influencing behavior. One can expect $\mathrm{d} S / \mathrm{d} x>0$ for $x \geq 0$ and $S(0)=0$ so that $S$ is the disutility from contributing less than the other players.

With social preferences, nonzero contributions to the public good can arise. As an illustration, suppose $S(x)=\max \{0, x\}$. If the social preference component of the payoff function is sufficiently high $\left(\sigma_{i}>1 / 4\right)$, the gap between other's contributions and earnings and the player's is harmful. Consequently, it is in the best interest of the decisionmaker to match the contributions of others. Any level of nonzero contribution, then, can be rationalized.

Consider a sequential public goods game. Suppose player 1 selects first, so that the other three players know his contribution prior to making their choices. It is straightforward to verify 
that the structure of the game (simultaneous versus sequential contributions) has no effect on the outcome if players are selfish $\left(\sigma_{i}=0\right)$ as $a_{\mathrm{i}}^{*}=0$ for all $i \in P$.

Proposition 1: In the sequential public goods game with selfish preferences $\left(\sigma_{i}=0\right.$ for all i), the unique Subgame Perfect Nash equilibrium entails complete free riding by both the leader and followers $\left(a_{i}^{*}=0\right.$ for all $\left.i\right)$, which matches the giving in the simultaneousmove public goods game with selfish preferences.

The decisionmaking in the sequential public goods game when players have social preferences differs from that in the normal-form game. Similar to that illustrated in Varian (1994), the leader, in a public goods giving environment, contributes less than the followers.

To formalize this claim suppose, as a second illustration, that $S(x)=x^{2}$. As in a Stackelberg Game, the followers (players 2, 3, and 4) best response to the known contribution of the leader (player 1). In the subgame perfect Nash equilibrium, then, the leader's choice not only affects his contribution to the public good, but acknowledges that his choice drives the decisions of the followers (due to their social preferences). In fact, the more he contributes, the less the followers do, while if he free rides, then the giving of the followers increases. The following proposition provides the Subgame Perfect Nash equilibrium with social preferences.

Proposition 2: In the sequential public goods game with social preferences (where the social preferences are not too low, i.e., $\sigma_{i}>\underline{\sigma}$ for all $i$ for a threshold $\underline{\sigma}>0$ ), the Subgame Perfect Nash equilibrium entails a (weakly) lower contribution by the leader, than the followers.

Thus, one would expect to see nonzero contributions if players have social preferences and in the sequential game leaders would give less than the followers.

An alternative payoff function, explored here, is that psychological preferences, rather than social preferences, explain contributions to public goods. The primary distinction between the two is that with social preferences, players care about the earnings of the other players (modeled here as a disutility from contributing less than the others). With psychological preferences players care about what others think of their actions. If a player believes that others 
expect a greater contribution out of him, then a greater disutility is experienced when free riding than when a player believes that others expect less from him. It is necessary to compare and contrast the anticipated contributions between players with selfish, social, and psychological preferences in both the normal-form and extensive-form public goods game to delineate the value of the competing mechanisms.

In Dufwenberg, Gächter, and Hennig-Schmidt (2011,p.462) a simultaneous-move public goods game with psychological preferences, which they refer to as a guilt-averse utility function, is formulated,

$$
\begin{aligned}
& u_{i}^{G}(a, c)=5-a_{i}+0.75\left(a_{1}+a_{2}+a_{3}+a_{4}\right)-\gamma_{i} \cdot \max \{0, \\
& \left.\left(c_{i j i}+c_{i k i}+c_{i l i}\right) / 3-a_{i}\right\}
\end{aligned}
$$

where $c_{i}=\left(c_{i j i}, c_{i k i}, c_{i l i}\right), i \neq j \neq k \neq l ; i, j, k, l \in P$, is the three third-order beliefs of $i$. The parameter $\gamma_{i} \geq 0$ measures the degree of guilt aversion, as it captures how important is deviating from the average of what $i$ believes the others expect out of him.

While both social preferences and psychological preferences generate a disutility from being different than other three players, the important contrast between the two is that social preferences model the difference in outcomes (contributions and earnings in the public goods game), while psychological preferences model how a player's giving differs from his expectations of what others believe he will play. It is this important distinction that matters for the mechanism's operation.

In the simultaneous-move game, again, nonzero contributions can be rationalized. For example, suppose $\gamma_{i}>1 / 4$. The best response from (3) is to select $a_{i}=\left(c_{i j i}+c_{i k i}+c_{i l i}\right) / 3$. Thus, if player $i$ believes others expect him to contribute generously, then he will do so. Consequently, numerous equilibria outcomes arise at varying levels of expectations, which are consistent with play in equilibrium.

Consider the extension to sequential contributions. As the leader, player 1's psychological preferences drive him to experience guilt if he does not "live up to" the expectations of the followers (or, more specifically, his beliefs of others' expectations of his behavior). Hence, let 


$$
u^{L}\left(a, c_{1}\right)=5-a_{1}+0.75\left(a_{1}+a_{2}+a_{3}+a_{4}\right)-\lambda_{1}\left\{\left(c_{1 j 1}+c_{1 k 1}+c_{1 l 1}\right) / 3-a_{1}\right\}
$$

be the utility function of one with psychological preferences of "leadership expectations." Thus, $\lambda_{1}=0$ represents standard, selfish preferences, while $\lambda_{1}>0$ is a player with psychological preferences for being a good leader. Furthermore, suppose followers experience guilt about contributing less than the leader. Hence, let

$$
u_{i}^{F}(a)=5-a_{i}+0.75\left(a_{1}+a_{2}+a_{3}+a_{4}\right)-\varphi_{i} F\left(a_{1}-a_{i}\right)
$$

be the payoff to a follower, $i \in\{2,3,4\}$. Thus, $\varphi_{i} \geq 0$ measures the degree to which free riding off the leader creates disutility to a follower, or rather, the importance placed on being a "good follower." Again, $\varphi_{i}=0$ represents the standard, selfish preferences, while $\varphi_{i}>0$ allows for other-regarding preferences. ${ }^{4}$

In the sequential public goods game, if psychological preferences of leadership expectations and being a good follower are not important to an individual $\left(\lambda_{1} \leq 0.25, \varphi_{i}=0\right)$, then the best response for the individual is to free ride, $a_{i}=0$. Followers care primarily about personal wealth and do not contribute. The leader, who does not put much weight on defying expectations, fails to provide, even partially, the public good.

Alternatively, suppose that others' expectations regarding the leader's role is important to the leader. Consequently, substantial leadership contributions arise, exceeding those driven solely by self-interest or social preferences, or that would arise in the simultaneous-move game. If there are no expectations on the followers' behavior, then their decision reverts back to the level driven solely by social preferences and/or utility from personal, financial wealth. Instead, if individuals care about following the leader, then nonzero contributions occur.

Proposition 3 provides a description of the equilibria under the assumption that $F\left(z_{i}\right)=z_{i}^{2}$ where $z_{i}=a_{1}-a_{i}$.

\footnotetext{
${ }^{4}$ One can add a guilt aversion term to the payoff function of the leader and followers as well without changing the main arguments presented. Also, one could replace $F\left(a_{1}-a_{i}\right)$ in equation (5) with $F\left(a_{1}-\left\{\left(c_{i j i}+c_{i k i}+c_{i l i}\right) / 3\right\}\right)$ where the followers' disutility is driven by psychological preferences rather than social preferences. The theoretical framework and experimental design, though, are unable to distinguish between the two setups.
} 
Proposition 3: In the sequential public goods game with psychological preferences, the leader contributes more to the public good than the followers.

One can model a number of theoretical frameworks to extend dynamic psychological game theory to sequential public goods contributions. The model provided, though, does illustrate how the theory can be applied to better understand the preferences of individuals. Testable predictions arise.

(1) In the simultaneous-move public goods game, zero contributions are expected out of selfish individuals, while positive contributions can be explained by either social preferences or psychological preferences.

(2) In the sequential public goods game, behavior does not change if individuals have selfish preferences.

(3) In the sequential public goods game, leaders contribute less than followers if individuals have social preferences.

(4) In the sequential public goods game, leaders contribute more than followers if individuals have social preferences.

Thus, the theoretical framework provides contrasting predictions based on the particular utility function describing players. Experimental data can be used to test these predictions to identify whether behavior is consistent with the theoretical framework provided.

\section{EXPERIMENTAL METHODS}

To address this issue experiments were conducted with undergraduate students at a small, private university in upstate New York. Subjects were recruited from general education classes. Additionally, individuals were recruited from classes within the business school. ${ }^{5}$ An online

\footnotetext{
${ }^{5}$ Economics is within the school of business and the faculty are joined with those in finance into one department.
} 
reservation manager was used to schedule the sessions. The recruitment strategy targeted students in classes taken by underclassmen, along with classes taken by upperclassmen, in both the general education courses and those within the business school.

A total of nine experimental sessions were conducted in November 2012 and April 2013. The number of participants in each session ranged from twelve to seventeen. There were a total of 147 experimental subjects. Each session lasted approximately one hour. Subjects completed a background information questionnaire and engaged in the experiment.

Two treatments were considered. In treatment 1 the subjects played the Public Goods Game. In this game, the subjects were randomly selected into groups of four. Each person in the group is endowed with five "experimental dollars" (hereafter E\$) and chose how much to contribute to a "common pot". The subjects were informed that the pot tripled and then was evenly shared amongst the four group members. In treatment 2 , the subjects played the Leadership Game. In it, again, the subjects were randomly selected into groups of four endowed with five E\$. First, subjects reported how much they would like to contribute to the common pot if selected to go first. One in the group was then selected at random. The members of the group were informed of this person's selection (but not identity) and asked how much they would like to contribute.

In the first two sessions the subjects engaged in treatment 1 and played five rounds of the game. In the next three sessions, subjects again engaged in treatment 1 and played six rounds. In the final four sessions the experimental volunteers first played two rounds of treatment 1 and then played four rounds of treatment 2. In each round of each treatment new random groupings were made to mitigate reputation, retaliation, and history-dependent play. Subjects made their initial decision not knowing who was in their group (not even the subjects' identification codes). Subjects were informed of their earnings from one round before making their selections in the next. The purpose of having subjects in the last four sessions conduct both treatments is to compare results in treatment 1 to those obtained by individuals in previous sessions to verify consistent behavior across the sample.

It was explained that the more experimental dollars they were able to earn in the rounds, the more real dollars they obtained. Specifically, the total number of experimental dollars earned by a subject in all rounds of play in a session would be aggregated. The total experimental dollars earned, then, would be converted into real dollars. The subjects were instructed that the 
amount they earned would be determined not only by the choices they made, but also were going to be affected by the choices of others. They were also informed that in previous, typical sessions (based on a pilot study) subjects earned on average over $\$ 20$, but the amounts ranged between $\$ 10$ and \$40. The payouts provided a \$10 “show-up" payment. A scale was adopted where if the maximum payoff was achieved in each round $\$ 50$ could be earned, down to a minimum of just the show-up fee. Payments were rounded to five dollar increments (or rather, a step-scale was developed). The average monetary payment received by a subject in the experiment was $\$ 22.50$.

The procedure used in each session was the following. After providing written, informed consent, the rules of the game were presented. PowerPoint slides and printed instructions were given. Individuals were also given the opportunity to ask questions. In treatment 1 individuals filled out a short form asking how much they would like to contribute. The paper forms were completed and random groupings were done at the podium in front of the subjects. The selections were scored and earnings were posted before conducting the second round. In treatment 2 individuals again filled out a short form choosing how much they would like to contribute if selected to be first. Again, random groupings were done in front of the subjects. On the spreadsheet projecting at the front of the room, each subject could see the first-mover's contribution. Then, after observing the leader's selection, each subject again filled out a form writing down how much they would like to contribute. Outcomes were then provided on the spreadsheet before playing the next round.

In sessions with a number of subjects not divisible by four, responses were selected at random to complete a four-person group and score it. Thus, for example, in a session with fifteen subjects, twelve are put into three groupings. Hence, this leaves three remainders. One of the twelve would be selected at random to provide the fourth contribution to the remaining three subjects. ${ }^{6}$

At the end of each experimental session one round of the Dictator Game was played. In it, subjects were informed they were to be paired with one other person, one of the two would be endowed with five E\$ and could choose how much they want to give to the other, endowed with nothing. The amount given would be tripled. The Dictator Game is commonly used as a control for altruistic giving motivations (Cox, 2004; List, 2007).

\footnotetext{
${ }^{6}$ Variation in the number of participants in each session is an artifact of students signing up for a session, but not showing up for it!
} 
With regards to the background information solicited, common demographic control variables were collected. They include gender, nationality, state of residence, major, and year in school. Also, given that the experiments occurred in November of 2012 and April 2013, each subject was asked whether or not $\mathrm{s} / \mathrm{he}$ had voted in the recent election. Previous work has shown that this correlates with "other-regarding" behavior (McCannon, 2014a). Table 1 provides descriptive statistics of the sample.

TABLE 1: DESCRIPTIVE STATISTICS

\begin{tabular}{lll}
\hline Variable & Description & Mean \\
\hline Dictator & amount given in the Dictator game & 1.542 \\
Vote & $=1$ if subject voted in November 2012 election & 0.519 \\
Male & $=1$ if subject is male & 0.646 \\
Business & $=1$ if subject is a business major & 0.655 \\
Freshman & $=1$ if subject is a freshman & 0.392 \\
Sophomore & $=1$ if subject is a sophomore & 0.142 \\
Junior & $=1$ if subject is a junior & 0.196 \\
Senior & $=1$ if subject is a senior & 0.263 \\
MBA & $=1$ if subject is an MBA student & 0.007 \\
USA & $=1$ if subject is a US citizen & 0.946 \\
NY & $=1$ if subject is from New York state & 0.726
\end{tabular}

The subject pool is dominated by U.S. citizens from the state of New York. There are more males than females, which is a result of oversampling from business classes. The sample contains both underclassmen and upperclassmen. In the Dictator Game, the average subject donated $30.8 \%$ of his/her endowment, which is in line with previous work (List, 2007).

\section{RESULTS}

Figure 1 graphically illustrates behavior in the Leadership Game (treatment 2) for the experimental sessions across the four rounds. The top panels present contributions of subjects conditioned on being the first-mover (top-left panel) and on being a second-mover (top-right panel). The bottom left panel depicts the actual giving, regardless of status. 
FIGURE 1: RESULTS ACROSS SESSIONS AND ROUNDS
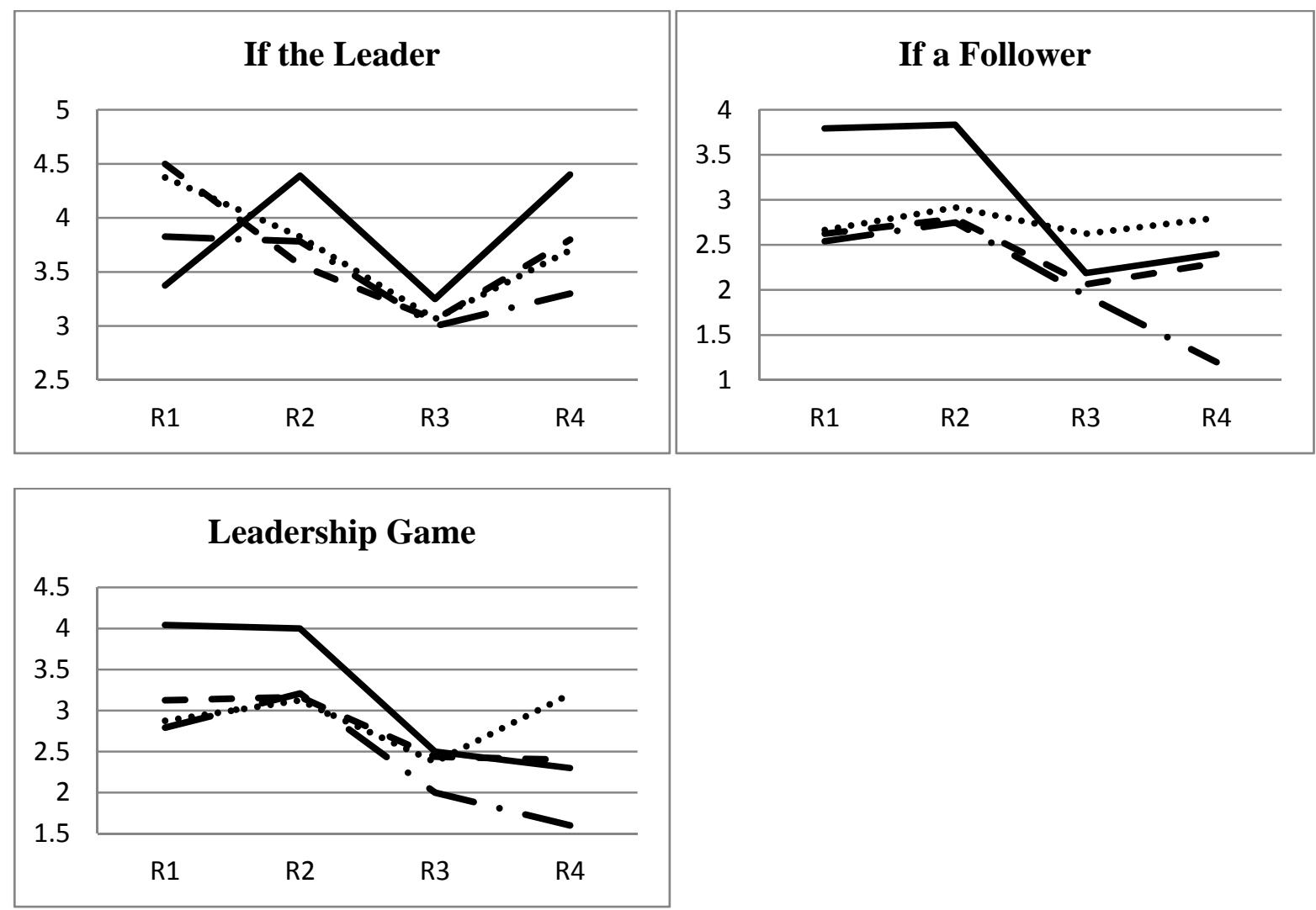

Each line presents the average amount given out of 5 for each session, across the four rounds (labeled R1-R4) The solid line is Session 6, the dotted line Session 7, the dashed line Session 8, and dash-dot line depicts Session 9. In Sessions $1-5$ only treatment 1 is conducted.

As stated, the top-left panel illustrates the offer if selected to be the leader, while the topright is the contribution if, instead, selected to be the follower in the Leadership Game. While leadership offers seem rather stable across rounds and sessions, the follower choices deteriorate over time across all sessions. This is in line with previous experimental findings in Public Good Games where contributions tend to reduce over time (Chaudhuri, 2010). Comparing the two panels, leader contributions exceed those of the followers, which is consistent with the results found in Levati, Sutter, and van der Heijden (2007), Güth, Levati, Sutter, and van der Heijden (2007), and Gächter, Nosenzo, Renner, and Sefton (2010; 2012), and show less deterioration over time, which is consistent with Arbak and Villeval (2013). The bottom-right panel provides the net result of the actual contributions in the Leadership Game. Again, a downward trend emerges.

Table 2 provides a summary of the choices made during the nine sessions. 
TABLE 2: PUBLIC GOODS CONTRIBUTIONS

\begin{tabular}{|c|c|c|c|c|}
\hline & Mean & $\%=5$ & $\%=0$ & $\%$ match \\
\hline \multicolumn{5}{|l|}{ Treatment 1} \\
\hline 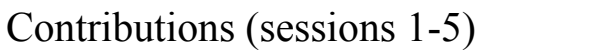 & 2.50 & $18.3 \%$ & $20.9 \%$ & \\
\hline Contributions (sessions 6-9) & 2.51 & $21.6 \%$ & $18.9 \%$ & \\
\hline \multicolumn{5}{|l|}{ Treatment 2} \\
\hline If selected to be the leader & 3.75 & $46.3 \%$ & $10.3 \%$ & \\
\hline If selected to be a follower & 2.71 & $27.7 \%$ & $19.9 \%$ & \\
\hline If the leader gave 5 , followers gave & 3.77 & $63.1 \%$ & $11.5 \%$ & $63.1 \%$ \\
\hline If the leader gave 4 , followers gave & 3.21 & $7.7 \%$ & $9.6 \%$ & $50.0 \%$ \\
\hline If the leader gave 3 , followers gave & 2.14 & $2.4 \%$ & $19.0 \%$ & $52.4 \%$ \\
\hline If the leader gave 2 , followers gave & 1.93 & $10.7 \%$ & $17.9 \%$ & $35.7 \%$ \\
\hline If the leader gave 1 , followers gave & 1.50 & $6.3 \%$ & $31.3 \%$ & $31.3 \%$ \\
\hline If the leader gave 0 , followers gave & 1.82 & $17.9 \%$ & $35.7 \%$ & $35.7 \%$ \\
\hline \multicolumn{5}{|c|}{ If selected to be a follower, but had offered 5 if chosen to be leader } \\
\hline \& leader gave 5 & 3.69 & $60.5 \%$ & $14.8 \%$ & \\
\hline$\&$ leader gave 4 & 3.07 & $14.3 \%$ & $14.3 \%$ & \\
\hline$\&$ leader gave 3 & 1.88 & $6.3 \%$ & $31.3 \%$ & \\
\hline$\&$ leader gave 2 & 1.67 & $11.1 \%$ & $33.3 \%$ & \\
\hline$\&$ leader gave 1 & 1.00 & $0.0 \%$ & $60.0 \%$ & \\
\hline$\&$ leader gave 0 & 2.07 & $14.3 \%$ & $28.6 \%$ & \\
\hline
\end{tabular}

Recall, sessions $1-5$ engaged in treatment 1 and sessions $6-9$ participated in treatment 2. Two rounds of treatment 1 were conducted in sessions $6-9$ to compare behavior across the cohorts. Thus, the two samples behave similarly.

The contributions in treatment 1 are in line with previous findings (Ledyard, 1995). In the standard, simultaneous-move Public Goods Game, subjects contribute 50\% of their endowment to the common fund. This is not consistent with selfish, wealth-maximizing behavior. In fact, in less than $20 \%$ of the observations was complete free riding witnessed.

With regards to the Leadership Game, striking results arise. If randomly selected to be the leader, subjects were willing to contribute, on average, $50 \%$ more than in the simultaneous-move game. A substantially higher proportion of the sample was willing to give their entire endowment and many fewer were willing to free ride. Interestingly, while still slightly higher 
than treatment 1 giving, when instead selected to be the follower in the sequential contribution game, subjects were willing to contribute much less (28\% less) than if the leader in the game. This suggests that individuals are motivated by others' beliefs about their behaviors, or rather, they have strong psychological preferences.

This is confirmed when considering, in Table 2, how followers responded to leaders' giving. Followers consistently, on average, lagged behind the leader with regards to the size of the contribution, but did adopt a form of a matching strategy where when the leader gave more, the followers tended to give more as well, but when the leader engaged in free riding so too did the followers. This result is consistent with the theoretical model of players motivated by otherregarding preferences. ${ }^{7}$

The experimental procedure implemented collected each subject's intended contribution if selected to be a leader, regardless of whether s/he was actually selected to be the leader. In addition, what the leader contributed to the group was made public, but not his/her identity, and each subject provided an actual contribution given the known amount offered by the leader. Thus, for each subject in each round both the offer if selected to be the leader and if selected to be the follower is provided. Thus, the final section of Table 2 provides information on the switching behavior of each subject. When an individual had offered to contribute five if selected to be the leader, how much that person did contribute once the leader's donation is shown. Consistently, those who had initially been willing to give all of their endowment pulled back their offer. As an extreme case, if an individual had been willing to give all five, but the selected leader only gives one dollar, then no one followed through with their initial offer and $60 \%$ did not make a contribution. Even when an individual would have been willing to give all five, and the leader actually gives five, almost $40 \%$ of the subjects reduce their actual contribution. In the full data set, subjects reduced downward their offer in over $52.8 \%$ of the observations.

Thus, strong evidence is provided that a significant component of an individual's desire to contribute to public goods is not strictly social preferences in that they just care about the well-being of others, but rather care about how other's perceive their actions and prefer to respond similarly to a leader.

\footnotetext{
${ }^{7}$ As discussed in footnote 5, the theoretical framework and experimental design is unable to distinguish social preferences, where the follower cares about his contribution differing from the leader's, and psychological preferences, where the follower cares about his assessment of others' beliefs regarding deviations from the leader's contribution. Thus, the broader "other-regarding preferences" descriptor is used here. The sequential nature of the game allows for a differentiation between the theories in the leader's preferences.
} 
Regarding wealth, the leaders, who tend to make greater contributions than the followers, average a payoff of $9.78 \mathrm{E} \$$, whereas the followers are able to generate $11.04 \mathrm{E} \$$.

To formalize these outcomes, econometric estimations are conducted with the dependent variable being the actual amount given to the public good. First, in the full data set (treatments 1 and 2 combined), the contrast between the simultaneous and sequential game can be analyzed. The indicator variable Leadership is equal to one if the observation came from sequential (treatment 2) experiments. In these sessions, the dummy variable Selected equals one if the subject in that round of the session was the one selected to be the leader. Background characteristics and round fixed effects (to account for potential deterioration in play) are included as controls. Table 3 presents the results with standard errors clustered by round of play to account for the possibility of less variation in play by a subject across rounds than across subjects within a round.

TABLE 3: FULL DATA SET RESULTS

(OLS, dependent variable $=$ Contribution, $N=822$ )

\section{Model 1}

$\begin{array}{llll}\text { constant } & 2.5920 & (0.2597) * * * & 2.6362 \\ \text { Selected } & & & 0.8049 \\ \text { Leadership } & 0.5526 & (0.1693) * * * & 0.3573 \\ \text { Male } & -0.3029 & (0.0837) * * * & -0.3178 \\ \text { Business } & 0.1832 & (0.1206) & 0.1734 \\ \text { Sophomore } & 0.0281 & (0.2006) & 0.0700 \\ \text { Junior } & 0.2677 & (0.2077) & 0.2310 \\ \text { Senior } & 0.4258 & (0.1139) * * * & 0.4297 \\ \text { MBA } & -2.2777 & (0.5689) * * * & -2.2416 \\ \text { USA } & -0.4085 & (0.1940) * * & -0.3973 \\ \text { NY } & 0.2657 & (0.1401) * & 0.2372 \\ \text { Vote } & 0.0324 & (0.0942) & 0.0041 \\ \text { Dictator } & 0.1073 & (0.0286) * * * & 0.1043 \\ & & & \text { YES } \\ \text { round controls? } & \text { YES } & & 0.048 \\ \text { adj. R } & & & 3290.1\end{array}$

Model 2

$(0.2675) * * *$

$(0.1855) * * *$

$(0.1751) * *$

$(0.0839) * * *$

$(0.1108)$

$(0.2084)$

$(0.1962)$

$(0.1183) * * *$

$(0.4564) * * *$

$(0.1951) * *$

$(0.1383) *$

$(0.0928)$

$(0.0296) * * *$ 
Observations that occur in the Leadership Game are associated with more giving. Thus, the net effect is less free riding with sequential contributions. Also, when the individual is selected to be the leader, a further increase in contributions arises. Thus, leadership is important for public good provision. Even, though, when a leader shirks the followers also free ride, the motivation to "look good" to the other subjects acts to increase the total amount of giving. The estimated effect is that leaders give $80 \mathrm{EC}$ more (16\% of their endowment) and followers give 36 EC more (7.2\% of their endowment) than in a standard Public Goods Game.

Many of the control variables are statistically significant. Even though an individual's choices were anonymous, gender and age are determinants of contributions (Sell, 1987). As to be expected, altruistic giving, measured by Dictator Game sharing, is correlated with public goods giving.

The results in Table 3 are robust. First, standard errors clustered by round of play are presented. If either heteroscedasticity-robust standard errors or standard errors clustered by session are calculated, then the coefficients of the main variables of interest remain highly significant. These additional calculations are presented in the appendix. Furthermore, if either the background control variables are dropped or session fixed effects are added, the significance of the results persist. Similarly, if the sixth round of treatment 1, which was played only in Sessions $3-5$ is excluded (so that all sessions of treatment 1 play five rounds) or if the two rounds of treatment 1 in Sessions 6-9 are dropped (which were used as a comparison to check the consistency of the two cohorts), then the main results continue to hold. Finally, the dependent variable takes discrete values between zero and five. The results presented treat it as an unbounded, continuous variable by using OLS to estimate the relationship. If, alternatively, an Ordered Logit model or a Poisson Count Data model is estimated, the sign and statistical significance of the main variables of interest remain. The estimations of these alternative models are presented in the appendix.

To understand better behavior in the sequential game, play in only rounds of the Leadership Game can be considered separately. Again, the dependent variable is the actual contribution to the public good. Along with background characteristics controls and round and session fixed effects, the publicly-known contribution of the leader, Leader, is included as a regressor. Again, clustered standard errors are reported. 
TABLE 4: LEADERSHIP GAME RESULTS

(OLS, dependent variable $=$ Contribution, $N=292)$

Model 1

\begin{tabular}{|c|c|c|c|c|}
\hline constant & 0.4112 & $(1.4846)$ & 0.6358 & $(1.5303)$ \\
\hline Selected & 0.8680 & $(0.2876) * * *$ & 0.8716 & $(0.3034) * * *$ \\
\hline Leader & 0.4265 & $(0.0295) * * *$ & -0.0647 & $(0.2708)$ \\
\hline Leader ${ }^{2}$ & & & 0.0906 & $(0.0435) * *$ \\
\hline Male & -0.2595 & $(0.1741)$ & -0.2753 & $(0.1778)$ \\
\hline Business & 0.6140 & $(0.0534) * * *$ & 0.5869 & $(0.0749) * * *$ \\
\hline Sophomore & 0.2782 & $(0.1551) *$ & 0.2913 & $(0.1217) * *$ \\
\hline Junior & 0.6544 & $(0.1849) * * *$ & 0.6742 & $(0.1438) * * *$ \\
\hline Senior & 0.7633 & $(0.5640)$ & 0.7729 & $(0.5317)$ \\
\hline$M B A$ & -1.2261 & $(0.7122) *$ & -1.2129 & $(0.6998) *$ \\
\hline$U S A$ & 0.4785 & $(1.4272)$ & 0.5015 & $(1.3236)$ \\
\hline$N Y$ & 0.1841 & $(0.1807)$ & 0.1747 & $(0.1577)$ \\
\hline Vote & -0.2798 & $(0.1387) * *$ & -0.2702 & $(0.1284) * *$ \\
\hline Dictator & 0.0186 & $(0.0497)$ & 0.0255 & $(0.0471)$ \\
\hline \multicolumn{5}{|l|}{ Controls: } \\
\hline round? & YES & & YES & \\
\hline session? & YES & & YES & \\
\hline $\operatorname{adj} . R^{2}$ & 0.263 & & 0.272 & \\
\hline AIC & 1118.2 & & 1115.7 & \\
\hline
\end{tabular}

\section{Model 2}

YES

0.272

1115.7

Thus, for each additional experimental dollar contributed by the leader an additional 43 EC is given by the individual ( $8.5 \%$ of their endowment), while when selected to be the leader the marginal impact on the actual contribution is estimated to be $87 \mathrm{EC}$.

Model 2 allows for a nonlinear effect of the leader's contribution and, again, confirms the previous findings. The positive impact of the leader's giving is important when the leader is more generous.

Again, the results presented in Table 4 are quite robust. The same main results persist if alternative standard errors are calculated (heteroskedastic-robust or clustered by session). Also, 
the main results hold when a Poisson Count Data model or an Ordered Logit is estimated. These additional estimations are presented in the appendix.

The previous results confirm that leaders and followers behave differently, even when the payoff structure remains unchanged. From the theoretical model, behavior is consistent with players having psychological preferences, rather than selfish or social preferences. What one wants to know, though, is what is it about the preferences of individuals in the experimental sessions that are driving the result. Could the results be explained by individuals simply placing a premium on being a leader and, thus, raising their contributions in isolation from the actions of others? Alternatively, are there psychological preferences at work where leaders lead based on their assessments of others' expectations, and followers' behavior is driven by their expectations about others', especially the leader's, beliefs about them? In the former a constant premium would be placed on leadership giving. In the latter, contributions and, specifically, the reversion in choices from being a leader to being a follower, should depend on the behavior of the firstmover.

To address this question, the variable Reversion is calculated. It is the difference between the amount an individual in a round is willing to contribute if selected to be the leader and the amount the same subject in the same round is willing to give if, instead, chosen to be the follower (now knowing what the leader actually contributes). The new dependent variable is measured in both level and as a percentage of the initial, leadership offer. ${ }^{8}$ Since Leader was shown to have a nonlinear effect on actual contributions of followers, the models reported in Table 5 also allow for such a relationship. Again, session and round fixed effects, background controls, and clustered standard errors are included and reported.

\footnotetext{
${ }^{8}$ The percentage calculation obviously has difficulties when the initial offer is zero. If the leader and follower offers are both zero, then the percentage change is recorded as a zero. Since the minimum value for nonzero leadership contributions is -4 (initially offer 1 and increase it to 5), then a move from offering 0 to 5 is recorded as -5 . Consequently, a change from 0 to 4 is recorded as $-4.8,0$ to 3 as $-4.6,0$ to 2 as -4.4 and 0 to 1 as -4.2 . Since the results in the second column (levels) of Table 5 mimic those of the first column (rates), this coding strategy does not seem to have an impact on the results.
} 
TABLE 5: REVERSION IN OFFERS

$(\mathrm{OLS}, N=292)$

Reversion (total)

\begin{tabular}{|c|c|c|c|c|}
\hline constant & -1.2835 & $(1.5568)$ & -1.9557 & $(1.4864)$ \\
\hline Leader & 0.5904 & $(0.1954) * * *$ & 0.3811 & $(0.0708) * * *$ \\
\hline Leader ${ }^{2}$ & -0.1301 & $(0.0483) * * *$ & -0.0710 & $(0.0040) * * *$ \\
\hline Male & 0.0499 & $(0.2320)$ & 0.1498 & $(0.0870) *$ \\
\hline Business & -0.1890 & $(0.5701)$ & 0.0765 & $(0.4137)$ \\
\hline Sophomore & -0.3167 & $(0.3493)$ & 0.00639 & $(0.1105)$ \\
\hline Junior & -0.7583 & $(0.4436) *$ & -0.0668 & $(0.2469)$ \\
\hline Senior & -0.3736 & $(0.6214)$ & -0.1367 & $(0.20237)$ \\
\hline$M B A$ & 3.4836 & $(0.9901) * * *$ & 0.7942 & $(0.3203) * *$ \\
\hline$U S A$ & 1.7909 & $(0.7576) * *$ & 1.3352 & $(1.1776)$ \\
\hline$N Y$ & 0.2804 & $(0.1475) *$ & 0.0950 & $(0.1514)$ \\
\hline Vote & 0.1866 & $(0.1524)$ & 0.0531 & $(0.0850)$ \\
\hline Dictator & -0.0233 & $(0.0512)$ & 0.0199 & $(0.0340)$ \\
\hline \multicolumn{5}{|l|}{ Controls: } \\
\hline round? & YES & & YES & \\
\hline session? & YES & & YES & \\
\hline $\operatorname{adj} . R^{2}$ & 0.119 & & 0.015 & \\
\hline AIC & 1260.9 & & 910.0 & \\
\hline
\end{tabular}

Reversion (\%)
The results in Table 5 provide strong evidence that the behavior of individuals is driven by the choices of others. Thus, the results are consistent with individuals who respond to their beliefs of others' expectations of their play when both the leader and the follower. Psychological preferences are an important driver of public goods contributions.

Again, the results in Table 5 are robust. The significance and sign of Leader and Leader ${ }^{2}$ hold if heteroskedastic-robust standard errors or standard errors clustered by session are calculated. Furthermore, suppose, instead, an indicator variable equal to one if and only if Reversion $>0$ is considered. The main results of Table 5 continue to hold if either a binary logit or probit is estimated. Additionally, as Arbak and Villeval (2013) an ordered variable is created equaling 0 if the following offer is greater, 1 if equal, and 2 if less than the offer if a leader is 
considered. The results hold when ordered logit and ordered probit are estimated. Finally, following Gächter, Nosenzo, Renner, and Sefton (2012), if leadership offer is used as the dependent variable and following offer is a control, actual leader giving has a separate, statistically significant effect showing that it is not just the characteristics of the subject, as illustrated by Gächter, Nosenzo, Renner, and Sefton (2012), but also the response to behaviors of others that determines contributions.

Figure 2 graphically illustrates the estimated reversion (y-axis) for differing levels of leader contributions (x-axis). Mean values for the background controls are used.

\section{FIGURE 2: RELATIONSHIP BETWEEN LEADER'S CONTRIBUTION AND REVISION}

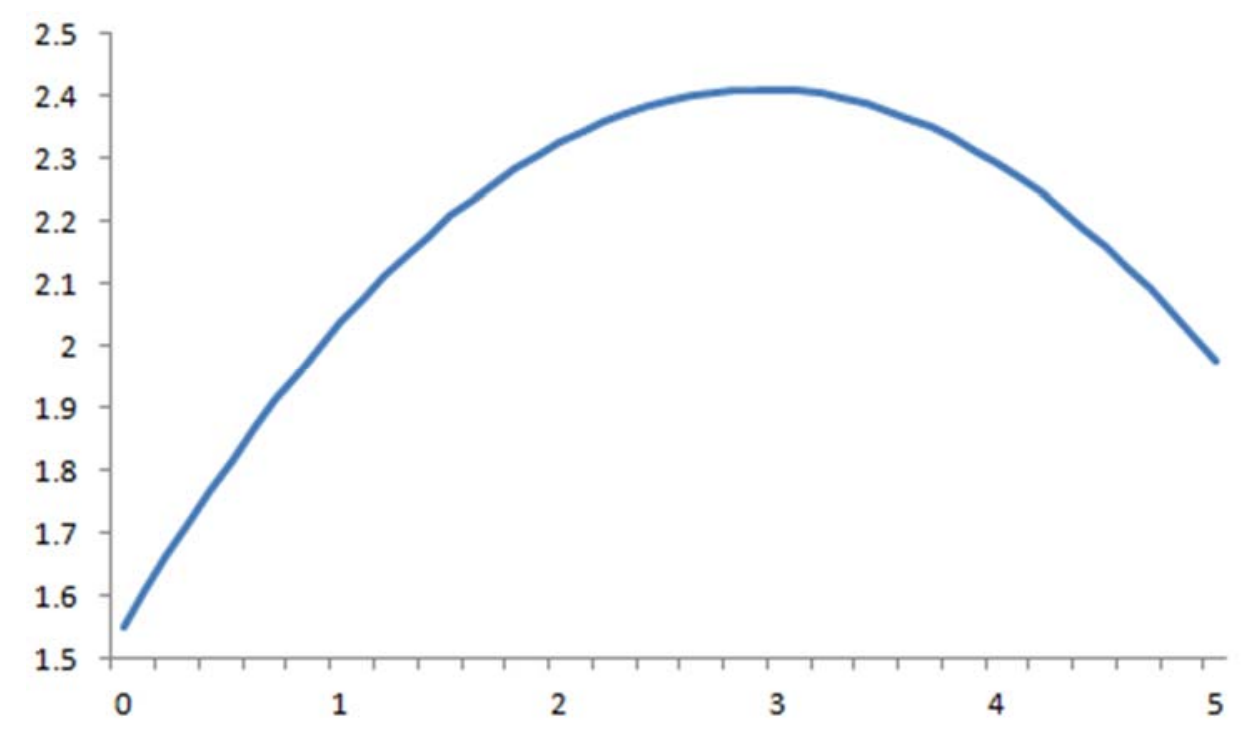

Thus, when the leader makes a generous contribution, subjects pull back their offers, but only modestly. Additionally, if the leader free rides, subjects also do not reduce their offers much. This is consistent with individuals "picking up the slack" for the leader. It is also consistent, from the theoretical model, to individuals having social preferences where the second-movers increase their contributions to reach a desirable level of group output. For intermediate contributions, though, reversion is large. 


\section{CONCLUSION}

The work explores the role of preferences, formulated in psychological game theory, in public goods contributions contrasting them with selfish preferences and the more commonly studied social .preferences. A simple theoretical model is developed that predicts those with social preferences behave differently than those with psychological preferences in sequential public goods games. The experimental results are consistent with psychological preferences, where individuals respond to their assessment of others' expectations regarding their behavior.

Sequential giving is able to encourage greater contributions out of the leader, as part of his utility is driven by his expectations regarding other's beliefs on his contribution. Motivated to "look good" the leader increases giving to a public good. Followers, also driven in part by their psychological preferences, "avoid the guilt" of free riding and adopt a quasi-matching strategy. Since the leader gives more (than in the standard, simultaneous-move public goods game), the followers contribute more increasing aggregate welfare. Thus, the results highlight not only the value in proper institutional design, but also highlight the importance of understanding the nature of individual utility functions.

The work builds on the well-established research on the optimal provision of public goods dating back to the seminal contribution of Groves and Ledyard (1977) and Ledyard and Palfrey (2002). The incorporation of behavioral economics insights into the free rider problem, as initiated by Andreoni $(1988 ; 1989 ; 1995)$, provides the opportunity to explore a wider range of analysis into the problem. An application of the important distinction between social preferences and psychological preferences can be found in Hallsworth, List, Metcalfe, and Vlaev (2014). They report on a field experiment providing information on the effect of unpaid taxes on society. Letters were sent to U.K. taxpayers encouraging them to pay. Notes pointing to being in the minority of non-payers generated greater payment rates than notes highlighting how others benefit from the public goods made possible with tax revenues. The former focuses on one's psychological preferences, while the latter relies only on the social preference of the taxpayer.

The framework explored is one of sequential giving. Alternatively, one could investigate further the role of punishment (Fehr and Gächter, 1992; 2000), conditional, contingent giving (Fischbacher, Gächter, and Fehr, 2001), communication (Isaac and Walker, 2000), repeated play (Fischbacher and Gächter, 2010), culture (Gächter and Hermann, 2009), and framing 
(Sonnemans, Shram, and Offerman, 1998) in public goods donations. Psychological preferences can be expected to affect behavior in these complementary environments. Thus, the role of psychological preferences in optimal institutional design of public goods contributions, along with any other number of economic environments that rely on non-selfish behavior, warrants further consideration.

The theoretical framework promotes psychological preferences as an important "otherregarding" preference that is expressed in sequential public goods environments. These preferences are contrasted to social preferences focusing utility on disparities in outcomes. One can be concerned that other competing theories of behavior can also explain the results provided. Hence, future research should consider additional economic environments in which to test psychological game theory as a dominant factor explaining behavior.

Finally, it is worth investigating potential covariates with psychological preferences. For example, Grossman, Komai, and Jensen (2015) provide evidence that there are important gender differences in leadership behavior when gender is revealed. If the genders differ in the degree to which they are socialized to put more weight on others' assessments of their behavior, or if a norm that "women believe that others' believe that women should sacrifice more (or contribute less) to a group's welfare" is pervasive, for example, gender and the salience of gender as found by Grossman, Komai, and Jensen (2015) would explain variation in giving levels. Similarly, economics education and beliefs regarding optimal economic policies have been shown to correlate with behavior in previous experiments (McCannon, 2014a; 2014b). The question has been raised as to whether education in economics has direct effects on outcomes, or are selection effects explaining differences in play. If education and policy arguments adjust invididuals' perceptions as to proper norms of behavior, as suggested by Marwell and Ames (1981), then a framework like the one developed here can be useful for formalizing and explaining such effects. These are just two potential examples of using psychological game theory to justify and identify differences in behavior and, hence, is a path for future research.

\section{REFERENCES}

Andreoni, James (1988), Why Free Ride? Strategies and Learning in Public Goods Experiments, Journal of Public Economics 37(3), 291-304. 
Andreoni, James (1989), Giving with Impure Altruism: Applications to Charity and Ricardian Equivalence, Journal of Political Economy 97(6), 1447-1458.

Andreoni, James (1995), Warm-Glow Versus Cold-Prickle: The Effects of Positive and Negative Framing on Cooperation in Experiments, Quarterly Journal of Economics 110(1), 1-21.

Andreoni, James (2006), Leadership Giving in Charitable Fund-Raising, Journal of Public Economics 8(1), 1-22.

Andreoni, James, Paul M. Brown, and Lise Vesterlund (2002), What Makes and Allocation Fair? Some Experimental Evidence, Games and Economic Behavior, 40(1), 1-24.

Andreoni, James and Ragan Petrie (2004), Public Goods Experiments Without Confidentiality: A Glimpse into Fund-Raising. Journal of Public Economics 88(7), 1605-1623.

Arbak, Emrah and Marie-Claire Villeval (2013), Voluntary Leadership: Motivation and Influence, Social Choice and Welfare 40(3), 635-662.

Battigalli, Pierpaolo and Martin Dufwenberg (2007), Guilt in Games, American Economic Review 97(2), 170-176.

Battigalli, Pierpaolo and Martin Dufwenberg (2009), Dynamic Psychological Game Theory, Journal of Economic Theory 144(1), 1-35.

Chaudhuri, Ananish (2011), Sustaining Cooperation in Laboratory Public Goods Experiments: A Selective Survey of the Literature, Experimental Economics 14(1), 47-83.

Cox, James C. (2004), How to Identify Trust and Reciprocity, Games and Economic Behavior 46(2), 260-281. 
Dufwenberg, Martin, Simon Gächter, and Heike Hennig-Schmidt (2011), The Framing of Games and the Psychology of Play, Games and Economic Behavior 73(2), 459-478.

Ertac, Seda and Mehmet Y. Gurdal (2012), Deciding to Decide: Gender, Leadership and RiskTaking in Groups, Journal of Economic Behavior \& Organization 83(1), 24-30.

Falkinger, Josef, Ernst Fehr, Simon Gächter, Rudolf Winter-Ebmer (2000), A Simple Mechanism for the Efficient Provision of Public Goods: Experimental Evidence, American Economic Review 90(1), 247-264.

Fehr, Ernst and Urs Fischbacher (2002), Why Social Preferences Matter - The Impact of Non-Selfish Motives on Competition, Cooperation and Incentives, Economic Journal 112(478), C1-C33.

Fehr, Ernst and Simon Gächter (1992), Altruistic Punishment in Humans, Nature 415(1), 137140 .

Fehr, Ernst and Simon Gächter (2000), Cooperation and Punishment in Public Goods Experiments, Nature 90(4), 980-994.

Fischbacher, Urs and Simon Gächter (2010), Social Prefernce, Beliefs, and the Dynamics of Free Riding in Public Goods Experiments, American Economic Review 100(1), 541-556.

Fischbacher, Urs, Simon Gächter, and Ernst Fehr (2001), Are People Conditionally Cooperative? Evidence from a Public Goods Experiment, Economic Letters 71(3), 397-404.

Gächter, Simon and Benedikt Hermann (2009), The Limits of Self-Governance when Cooperators Get Punished: Experimental Evidence from Urban and Rural Russia, European Economic Review 55(2), 193-210. 
Gächter, Simon, Danielle Nosenzo, Elke Renner, and Martin Sefton (2010), Sequential vs. Simultaneous Contributions to Public Goods: Experimental Evidence, Journal of Public Economics 94(7), 515-522.

Gächter, Simon, Danielle Nosenzo, Elke Renner, and Martin Sefton (2012), Who Makes a Good Leader? Cooperativeness, Optimism, and Leading-By-Example, Economic Inquiry 50(4), 953967.

Geanakoplos, John, David Pearce, and Ennio Stacchetti (1989), Psychological Games and Sequential Rationality, Games and Economic Behavior 1(1), 60-79.

Grossman, Philip J., Mana Komai, and James E. Jensen (2015), Leadership and Gender in Groups: An Experiment, Canadian Journal of Economics (forthcoming).

Groves, Theodore and John O. Ledyard (1977), Optimal Allocation of Public Goods: A Solution to the "Free Rider" Problem, Econometrica 45(4), 783-810.

Güth, Werner, M. Vittoria Levati, Matthias Sutter, Eline van der Heijden (2007), Leading by Example with and without Exclusion Power in Voluntary Contribution Experiments, Journal of Public Economics 91(5-6), 1023-1042.

Haigner, Stefan D. and Florian Wakolbinger (2010), To Lead or Not to Lead: Endogenous Sequencing in Public Goods Games, Economics Letters 108(1), 93-95.

Hallsworth, Michael, John A. List, Robert D. Metcalfe, and Ivo Vlaev (2014), The Behavioralist As Tax Collector: Using Natural Field Experiments to Enhance Tax Compliance, National Bureau of Economic Research, No. w20007.

Hermalin, Benjamin E. (1998), Toward an Economic Theory of Leadership: Leading By Example, American Economic Review 88(5), 1188-1206. 
Huang, Peter H. and Ho-Mou Wu (1994), More Order without More Law: A Theory of Social Norms and Organizational Cultures, Journal of Law, Economics \& Organization 10(2), 390-406.

Isaac, R. Mark, Kenneth F. McCue, and Charles R. Plott (1985), Public Goods Provision in an Experimental Environment, Journal of Public Economics 26(1), 54-74.

Isaac, R. Mark and James M. Walker (2000), Communication and Free-Riding Behavior: A Voluntary Contribution Mechanism, Economic Inquiry 26(4), 585-608.

Komai, Mana, Philip J. Grossman, and Travis Deters (2011), Leadership and Information in a Single-Shot Collective Action Game: An Experimental Study, Managerial and Decision Economics 32(1), 119-134.

Komai, Mana and Mark Stegeman (2010), Leadership Based on Asymmetric Information, RAND Journal of Economics 41(1), 35-63.

Komai, Mana, Mark Stegeman, and Benjamin E. Hermalin (2007), Leadership and Information, American Economic Review 97(3), 944-947.

Lazear, Edward P. (2012), Leadership: A Personnel Economics Approach, Labour Economics 19(1), 92-101.

Ledyard, John O. (1995), Public Goods: A Survey of Experimental Research, in Alvin E. Roth and John H. Kagel (eds.), Handbook of Experimental Economics, Princeton University Press, 111-181.

Ledyard, John O. and Thomas R. Palfrey (2002), The Approximation of Efficient Public Good Mechanisms by Simple Voting Schemes, Journal of Public Economics 83(2), 153-171. 
Levati, M. Vittoria, Matthias Sutter, and Eline van der Heijden (2007), Leading by Example in Public Goods Experiment with Heterogeneity and Incomplete Information, Journal of Conflict Resolution 51(5), 793-818.

List, John A. (2007), On the Interpretation of Giving in Dictator Games, Journal of Political Economy 115(5), 482-493.

Marwell, Gerald and Ruth E. Ames (1981), Economists Free Ride, Does Anybody Else? Journal of Public Economics 15(3), 295-310.

McCannon, Bryan C. (2014a), Do Economists Play Well With Others? Experimental Evidence on the Relationship between Economics Education and Pro-Social Behavior, American Economist 59(1), 1-7.

McCannon, Bryan C. (2014b), Trust, Reciprocity, and a Preference for Economic Freedom: Experimental Evidence, Journal of Institutional Economics 10(3), 451-470.

Potters, Jan, Martin Sefton, and Lise Vesterlund (2005), After You - Endogenous Sequencing in Voluntary Contribution Games, Journal of Public Economics 89(8), 1399-1419.

Potters, Jan, Martin Sefton, and Lise Vesterlund (2007), Leading-by-Example and Signaling in Voluntary Contribution Games: An Experimental Study, Economic Theory 33(1), 169-182.

Rivas, M. Fernanda and Matthias Sutter (2011), The Benefits to Voluntary Leadership in Experimental Public Goods Games, Economics Letters 112(2), 176-178.

Sell, Jane (1987), Gender, Strategies, and Contributions to Public Goods, Social Psychology Quarterly 60(3), 252-265. 
Sonnemans, Joep, Arthur Schram, and Theo Offerman (1998), Public Goods Provision and Public Bad Prevention: The Effect of Framing, Journal of Economic Behavior and Organization 34(1), 143-161.

Van Vugt, Mark and David De Cremer (1999), Leadership in Social Dilemmas: The Effects of Group Identification on Collective Actions to Provide Public Goods, Journal of Personality and Social Psychology 76(4), 587-599.

Varian, Hal R. (1994), Sequential Contributions to Public Goods, Journal of Public Economics 53(1), 165-186.

Vesterlund, Lise (2003), The Informational Value of Sequential Fundraising, Journal of Public Economics 87(3-4), 627-657.

Weber, Roberto, Colin Camerer, Yuval Rottenstreich, and Marc Knez (2001), The Illustion of Leadership: Misattribution of Cause in Coordination Games, Organizational Science 12(5), 582598.

Zellmer, Jennifer (2003), Linear Public Goods Experiments: A Meta-Analysis, Experimental Economics 6(3), 299-310. 


\section{APPENDIX}

Proof of Proposition 1: Using the utility function in (1) it follows that $\mathrm{d} u_{i} W / \mathrm{d} a_{i}=-1 / 4<0$. In each subgame, then, $a_{2} *=a_{3} *=a_{4} *=0$. Consequently, $a_{1} *=0$, which constitutes the unique Subgame Perfect Nash equilibrium. Obviously, then, the outcome remains if the simultaneousmove game is considered.

Lemma 1: In the Nash equilibrium of the simultaneous-move public goods game with social preferences, if $S(x)=x^{2}$ or if $S(x)=\max \left\{0, \bar{a}_{l}-a_{i}\right\}$ and $\sigma_{i}<1 / 4$ for all $i$, then each player contributes $a_{i}^{*}=0$. If $S(x)=\max \left\{0, \overline{a_{l}}-a_{i}\right\}$ and $\sigma_{i} \geq 1 / 4$ for all $i$, then any $a^{*} \in[0$, 5] where $a_{1} *=a_{2} *=a_{3} *=a_{4} *=a^{*}$ is a Nash equilibrium.

Proof of Lemma 1: Using the payoff function in (2) and the assumption that $S(x)=x^{2}, \mathrm{~d} u_{i} S / \mathrm{d} a_{i}$ $=-1 / 4+2 \sigma_{i}\left(\overline{a_{l}}-a_{i}\right)$. First, if $\overline{a_{l}}>a_{i}$, then an increase to $a_{i}+\varepsilon$ results in a payoff of $5-a_{i}-\varepsilon+$ $0.75\left(a_{1}+a_{2}+a_{3}+a_{4}+\varepsilon\right)-\sigma_{i}\left(\overline{a_{l}}-a_{i}-\varepsilon\right)^{2}$. In a symmetric Nash equilibrium $\left(a_{1} *=a_{2} *=a_{3} *=\right.$ $\left.a_{4}^{*}=a^{*}\right)$ this simplifies to $5-a^{*}-\varepsilon+0.75\left(3 a^{*}+a^{*}+\varepsilon\right)-\sigma\left(a^{*}-a^{*}-\varepsilon\right)^{2}=5+2 a^{*}-0.25 \varepsilon-$ $\sigma_{i} \varepsilon^{2}$, which is decreasing in $\varepsilon$. Second, if $\overline{a_{l}} \leq a_{i}$, then, again, the payoff is decreasing in $\varepsilon$. Thus, the best response is $a_{i}=0$, so that the symmetric Nash equilibrium is $a_{1} *=a_{2} *=a_{3} *=a_{4} *=0$.

Alternatively, using the payoff function in (2) and the assumption that $S(x)=\max \left\{0, \overline{a_{l}}-\right.$ $\left.a_{i}\right\}, \mathrm{d} u_{i}^{S} / \mathrm{d} a_{i}=-1 / 4+\sigma$ when $\overline{a_{l}}>a_{i}$ and $\mathrm{d} u_{i}^{S} / \mathrm{d} a_{i}=-1 / 4$ when $\overline{a_{l}} \leq a_{i}$. First, if $\sigma_{i} \leq 1 / 4$ for all $i$, then $\mathrm{d} u_{i} S / \mathrm{d} a_{i} \leq 0$ and the best response is $a_{i}=0$. Hence, if $\sigma_{i} \leq 1 / 4$ for all $i$, then the symmetric Nash equilibria entail $a_{1} *=a_{2} *=a_{3} *=a_{4} *=0$. Second, if $\sigma_{i}>1 / 4$ and $\overline{a_{l}}>a_{i}$, then a deviation to $a_{i}$ closer to $\overline{a_{l}}$ is profitable. Thus, consider $\overline{a_{l}}=a_{i} \equiv a^{+}$. If this is adopted by all players, this generates a payoff to each of $5-a^{+}+0.75\left(4 a^{+}\right)=5+2 a^{+}$. A deviation by a player to $a^{+}-\varepsilon$ results in $5-a^{+}+\varepsilon+0.75\left(4 a^{+}-\varepsilon\right)=5+2 a^{+}-0.25 \varepsilon$, which is less for any value of $\varepsilon$. Hence, if $\sigma_{i}>1 / 4$ for all $i$, then the symmetric Nash equilibria entail $a_{1} *=a_{2} *=a_{3} *=a_{4} *=a^{*}$ and any value of $a^{*} \in[0,5]$ can be rationalized.

Proof of Proposition 2: Suppose $S(x)=x^{2}$. First, consider the decisionmaking of players 2, 3, and 4 in the subgames. Let $\widehat{a_{1}}$ denote the known contribution made by player 1 . Consider player $j, j \in\{2,3,4\}$ where $u_{j}^{S}=5-a_{j}+0.75\left(a_{1}+a_{2}+a_{3}+a_{4}\right)-\sigma_{j}\left(\overline{a_{J}}-a_{j}\right)^{2}$ where $\overline{a_{j}}=\left(a_{i}+a_{k}+a_{l}\right) / 3$, $j \neq i, k, l$. The best response for player $j$ is $a_{j}=\overline{a_{j}}-1 / 8 \sigma_{j}$. In the symmetric equilibrium of the subgame, $a_{f}^{*}$ (the contribution of a follower) is $1 / 8 \sigma_{f}-\widehat{a_{1}}$. Now, using backward induction, consider the contribution by player 1 . The payoff is $u_{1} S=5-a_{1}+0.75\left(3 / 8 \sigma_{1}-2 a_{1}\right)-\sigma_{1}\left(1 / 8 \sigma_{1}-\right.$ $\left.2 a_{1}\right)^{2}$ so that $\mathrm{d} u_{1} S / \mathrm{d} a_{1}=-2.25-4 \sigma a_{1}<0$. Consequently, the unique Subgame Perfect Nash equilibrium has $a_{1} *=0$ and $a_{f}^{*}=1 / 8 \sigma_{f}$. It follows from Lemma 1 that the leader contributes (weakly) less, while the followers contribute more, than in the simultaneous-move game.

Alternatively, suppose $S(x)=\max \left\{0, \overline{a_{l}}-a_{i}\right\}$. Again, following backwards induction, consider the decisionmaking of 2,3 , and 4 in the subgames. It follows that $\mathrm{d} u_{j} S / \mathrm{d} a_{j}=-1 / 4+\sigma_{j}$ when $\overline{a_{\imath}}>a_{i}$ and $\mathrm{d} u_{j} S / \mathrm{d} a_{j}=-1 / 4$ when $\overline{a_{\imath}} \leq a_{i}$. If $\sigma_{j}>1 / 4$, then $\mathrm{d} u_{j} S / \mathrm{d} a_{j}>0$ when $\overline{a_{j}}>a_{j}$ and deviation of $a_{j}$ closer to $\overline{a_{j}}$ is profitable. Thus, again, consider $\overline{a_{l}}=a_{i} \equiv a^{+}$for $i \in\{2,3,4\}$. If this is adopted by players 2,3 , and 4 , then this generates a payoff to each of $5-a^{+}+0.75\left(4 a^{+}-\theta\right)=$ $5+2 a^{+}-0.75 \theta$ where $\theta$ is any difference between the leader's contribution, $a^{+}-\theta$, and the followers. A deviation by a player in $\{2,3,4\}$ to $a^{+}-\varepsilon$ results in $5-a^{+}+\varepsilon+0.75\left(4 a^{+}-\varepsilon-\theta\right)=$ $5+2 a^{+}-0.25 \varepsilon-0.75 \theta$, which is less for any value of $\varepsilon$. Thus, $a^{+}=\overline{a_{\iota}}$ must hold in equilibrium. As a result, $\overline{a_{l}}=3 a^{+}-\theta$, so that combining the two, $2 a^{+}=\theta$, or rather, $a^{+}=\theta / 2$ (assuming $\theta>0$; 
otherwise $\left.a^{+}=0\right)$. Now, consider the initial decision by the leader - player 1 . His choice of $\theta$ results in a utility of $5-a^{+}+\theta+0.75\left(3 \theta / 2+a^{+}-\theta\right)-\sigma_{1} \max \left\{0, \theta / 2-a^{+}+\theta\right\}$, which simplifies to $5-0.25 a^{+}+7 \theta / 4-\sigma_{1} \max \left\{0,3 \theta / 2-a^{+}\right\}$. If $3 \theta / 2<a^{+}$, then $\mathrm{d} u 1^{S} / \mathrm{d} \theta>0$ and $\theta=a^{+}=0$. If $3 \theta / 2 \geq a^{+}$, then $\mathrm{d} u_{1} S / \mathrm{d} a_{1}=7 / 4-3 \sigma_{1} / 2$, which is less than zero when $\sigma_{1}>7 / 6$. In this case $\theta=$ $2 a^{+} / 3$ so that in equilibrium $a_{1}=a^{+} / 3$. Otherwise, if $\sigma_{1} \leq 7 / 6$, then $\mathrm{d} u 1^{S} / \mathrm{d} \theta>0$ and $\theta=a^{+}$. As a result, if $\sigma_{1} \leq 7 / 6$, then $a_{1} *=a_{2} *=a_{3} *=a_{4} *=0$, while if $\sigma_{1}>7 / 6$, then any $a^{*} \in[0,5]$ for players 2, 3, and 4 with $a_{1} *=a^{*} / 3$ is a Subgame Perfect Nash Equilibrium.

Corollary 2: The Subgame Perfect Nash equilibrium of the sequential public goods game with social preferences (and selfish preferences as well) generates less than the sociallyoptimal (aggregate utility maximizing) level of public goods giving, which is $a_{1}=a_{2}=a_{3}$ $=a_{4}=5$.

Proof of Corollary 2: Let $W=\Sigma u_{i}^{S}$. Here $W=20-\left(a_{1}+a_{2}+a_{3}+a_{4}\right)+3(0.75)\left(a_{1}+a_{2}+a_{3}+\right.$ $\left.a_{4}\right)-\sigma_{i} \Sigma S\left(x_{i}\right)$. It follows immediately that for any sum $\left(a_{1}+a_{2}+a_{3}+a_{4}\right), W$ is improved if $a_{1}=$ $a_{2}=a_{3}=a_{4} \equiv a$. Hence, $W=20+0.75\left(a_{1}+a_{2}+a_{3}+a_{4}\right)=20+3 a$, which is maximized at $a=5$. Thus, the socially-optimal level of contribution for each player, whether $\sigma_{i}=0$ or $\sigma_{i}>0$, is not reached in the Subgame Perfect Nash equilibrium of Proposition 1 (selfish preferences) and Proposition 2 (social preferences).

Table A1 presents additional standard error calculations for the primary independent variables in Table 3 and Table 4. In the parentheses the heteroscedasticity-robust standard error is calculated. In the brackets are the standard errors clustered by session. One may be concerned about variation between sessions. While the experimental design included randomly selected, new pairings in each round of the game, it is reasonable to be concerned about norms arising within a session. Thus, the variation in play within a session may be less than the variation between sessions. Additionally, since the choice variable is bounded to be between zero and five, the variation in outcomes may be less at or near the boundaries. Therefore, independent variables, which correlate with being near a boundary, could be correlated with the variance of the residual term. This could lead to heteroscedasticity. Hence, heteroscedasticity-robust standard errors are reported. 
TABLE A2: ALTERNATIVE MODELS

(dependent variable $=$ Contribution $)$

\begin{tabular}{|c|c|c|c|c|}
\hline & $\begin{array}{l}\text { Full Sample } \\
\text { Ordered Logit }\end{array}$ & Count Data & $\begin{array}{l}\text { Leadership Game } \\
\text { Ordered Logit }\end{array}$ & Count Data \\
\hline Selected & $\begin{array}{l}0.8270 \\
(0.2612) * * *\end{array}$ & $\begin{array}{l}0.2545 \\
(0.0708) * * *\end{array}$ & $\begin{array}{l}0.9160 \\
(0.2202) * * *\end{array}$ & $\begin{array}{l}0.2672 \\
(0.0565) * * *\end{array}$ \\
\hline Leadership & $\begin{array}{l}0.3974 \\
(0.1613) * *\end{array}$ & $\begin{array}{l}0.1330 \\
(0.0585) * *\end{array}$ & & \\
\hline Leader & & & $\begin{array}{l}0.5512 \\
(0.1032) * * *\end{array}$ & $\begin{array}{l}0.1748 \\
(0.0341) * * *\end{array}$ \\
\hline Dictator & $\begin{array}{l}0.1127 \\
(0.0483) * *\end{array}$ & $\begin{array}{l}0.0372 \\
(0.0157) * *\end{array}$ & $\begin{array}{l}0.0356 \\
(0.0820)\end{array}$ & $\begin{array}{l}0.0038 \\
(0.0218)\end{array}$ \\
\hline $\begin{array}{l}\text { Controls: } \\
\text { background? } \\
\text { round? } \\
\text { session? } \\
\text { adj. R }{ }^{2} \\
\text { AIC }\end{array}$ & $\begin{array}{l}\text { YES } \\
\text { YES } \\
\text { NO }\end{array}$ & $\begin{array}{l}\text { YES } \\
\text { YES } \\
\text { NO } \\
0.0100 \\
3316.6\end{array}$ & $\begin{array}{l}\text { YES } \\
\text { YES } \\
\text { YES }\end{array}$ & $\begin{array}{l}\text { YES } \\
\text { YES } \\
\text { YES } \\
0.0589 \\
1142.5\end{array}$ \\
\hline
\end{tabular}

As one can see, the sign and statistical significance of the coefficients of the primary variables of interest persist. 